\title{
Proceeding
}

Supplementary Issue: Autumn Conferences of Sports Science. Costa Blanca Sports Science Events, 18-19 December 2020. Alicante, Spain.

\section{Field survey for observation of motor development in childhood age using the MOVIT tool}

\author{
LUCIA PALLONETTO $\triangleleft$, ROSANNA PERRONE, CARMEN PALUMBO \\ Department of Human, Philosophical and Educational Sciences, University of Salerno, Italy
}

\begin{abstract}
The study aims to highlight the role of corporeity in the development of the child by focusing on the dimension of movement considered as the origin of cognitive and learning processes (Sibilio M., 2008). In addition, we want to support the function that the body itself can play as a mediator of knowledge for the design of educational paths, focused on recreational-motor activities always to enhance the potential of the body and motor experience (Palumbo C., 2018). Field research involved a sample of 84 children, to whom Movit Trials (Cottini L., 2003) were given in a playful form, both in-and-out. The latter constitute a psychomotor evaluation tool that provides an objective assessment of the current and potential abilities, deficits and development of the child observed in his environment and in free interaction with his companions. Games and activities of free or guided movement can, therefore, be an opportunity for «health education» and movement, helping the child to build his own identity, «to the satisfaction of the control of gestures, in coordination with others» (D.M. 2012). The survey allowed to evaluate any delays in typical motor development, defining the criticality and potential of the specific ages of the subjects.
\end{abstract}

Keywords: Corporeity; MOVIT; Motor development; Recreational activity.

\section{Cite this article as:}

Pallonetto, L., Perrone, R., \& Palumbo, C. (2021). Field survey for observation of motor development in childhood age using the MOVIT tool. Journal of Human Sport and Exercise, 16(2proc), S565-S573. doi:https://doi.org/10.14198/ihse.2021.16.Proc2.40

Corresponding author. Department of Human, Philosophical and Educational Sciences, University of Salerno, Italy.

E-mail: Ipallonetto@unisa.it

Abstract submitted to: Autumn Conferences of Sports Science. Costa Blanca Sports Science Events, 18-19 December 2020. Alicante, Spain.

JOURNAL OF HUMAN SPORT \& EXERCISE ISSN 1988-5202

(c) Faculty of Education. University of Alicante

doi:10.14198/jhse.2021.16.Proc2.40 


\section{INTRODUCTION}

To date, new realities of support and care for learners have taken place in the field of education, as the importance of body culture has emerged. Indeed, body experience cannot simply be implemented as a subsidiary or supplementary dimension of educational care and learning development. The "actors" involved in the educational relationship must renew their understanding of the "educational" environment as a stimulus and as a resource for the full realization of body and gestural identity.

In this perspective, corporeity plays a key role in the modern organization that emerges in terms of sensory, perceptive and cognitive awareness. According to the Embodied perspective, the first way of access and elaboration of any knowledge (mathematics, Italian, a new language) is found right in the body. If we go back to the school of childhood, a first exploratory mode makes use of the five senses for the field of experience the Knowledge of the world, and in a transversal way with "the body and the movement".

«In the first cycle, physical education promotes the knowledge of oneself and of one's own potential in the constant relationship with the environment, the others, the objects. It also contributes to the formation of the student's personality through the knowledge and awareness of his own body identity, as well as the continuous need for movement as a constant care of his own person and well-being. [...] Motor education and play is therefore an opportunity to promote cognitive, social, cultural and emotional experiences. Through the movement, with which a wide range of gestures is realized, ranging from the mimic of the face, to the dance, to the most varied sports performances, the pupil will be able to know his body and explore the space, communicate and relate with others in an appropriate and effective way» (D.M. 2012).

Thus, the need for movement education that takes into account the experiences and that tends to consolidate lifestyles that require the enhancement of motor and sports experiences for preventive purposes to combat any involution of motor skills.

Recreational motor-sports activities encourage reflection on the changes of one's own body on the part of children, and this is the way in which growth and the process of maturation have their greatest expression. This allows the child to have an image of himself that can also be taken in comparison with peers.

Participate in motor and sports activities and share group experiences, also promotes the inclusion of pupils with disabilities, making you understand the true value of cooperation and teamwork (D.M. 2012).

The playful experience offers the child the opportunity to proceed in his evolutionary path, in a spontaneous way, through reworking of archaic experiences, within new contexts; from this it is clear that even in this stage, the game allows the child to structure new personality traits (Downing G.,1995). In fact:

"The game, [...] has a crucial role in communication, in education to respect shared rules, in the development of strategies suitable for different contexts» (MIUR 2012).

To endorse these theses, contribute, more recently and significantly, the neurosciences, which emphasize the role played by experience in the construction of brain anatomy. According to the most recent scientific research, the early development of the brain, almost independent from the environment, during the very first phases, becomes strongly conditioned by the latter, after the birth. Experience, in fact, helps to refine neuronal connections, and to develop functional specializations. It has been established that the development of brain structures and functions is subject to changes due to experiences affecting the genetically determined characteristics of the central nervous system (Muratori F., 2008). 
The identification of this space continues in the reflections of subsequent studies on mirror neurons for which: "The creation of this shared space would be the result of this incarnate simulation activity, which in turn is defined in sub personal terms by the activity of mirror neurons that allow the mapping of actions performed and observed on the same nerve substrate, feelings and emotions experienced personally and observed in others» (Gallese V. in Gison G., et al., 2012).

A game-centred approach places learning within the game (Kirk D., \& Macphail A, 2002), whose goal is to better connect students and their skills (both physical and cognitive) to the needs of the game. This approach requires students to interact with individual constraints (physical attributes, functional characteristics), environmental (physical and social conditions) and tasks (rules, tools) placed on them (Chow J., et al., 2007).

Games are a means of education, through which it is possible to influence students in a positive way. Each game, with its content, educational objective, rules and game-action, forms the mind, the spirit of observation, self-control, discipline, imagination, creativity, spontaneity and the desire to know. Through games, we can monitor the acquisition of knowledge, the consolidation of knowledge already acquired and then assess the level of training of students. The educational features of the educational game make learning more flexible, gentle and comfortable. We can say that games, activities that allow children to be themselves, are the link between school and life.

In the light of psychopedagogical studies and the contribution of neuroscience, it is necessary that the overcoming of the Cartesian dualism body mind occurred in theory, be applied in educational practices. It is important that, especially those who work with the children of the basic school, know and recognize the educational value of the game itself:

"It knows the functions, the forms, the tie with the construction of the identity, the education and the pathology - and still - that it acquires the necessary competences so that it can intentionally propose it, adequately to support it and above all to make it evolve, enhancing its educational potential» (Formenti L.,2006).

"To express its originality and to conquer the world, the child needs to be able to live its omnipotence, that is, the motor drive that accompanies its actions» (Aucouturier B., 2007).

However, the harmonious development of the child presupposes the possibility of:

«To exist as a single subject and to express one of his particular and specific discourses connected to the events of his personal history, allowing a psychological maturation that favours the development of the pleasure of thinking, creating and communicating» (Aucouturier B., 2007).

Each child has its own and original way of internalizing the reality that surrounds him, of thinking and rethinking it, of interpreting it according to its own codes and of living it playfully.

The game, moreover, is the natural approach that the child has towards reality, a playful dimension, in which, pass all forms of construction of linguistic, logical, scientific and motor skills. The task of the educator, therefore, consists in providing functional playful experiences and has, among the tools at its disposal, different games that evolve together with the stages of life of the child.

\section{METHODS}

The main idea of the project was to offer children a path of bodily experiences through practical activities. The teacher's task has been to plan fun activities based on the skills detected in the entrance and encourage 
their evolution along with the progress of children, in order to highlight the repercussions of the outgoing intervention preserving the methods of play and observation, "in continuity" with the tests used. The selected 'qualitative' survey tool (Lucisano, P. \& Salerni, A., 2002) was carried out by identifying the Movit test screening tool (Cottini L., 2013) and lasted six months.

\section{Tools}

The standardized Movit tests allow to conduct a systematic and ecological observation of the psychomotor area through 7 scales referring to the following components: Tone and relaxation; Balance and general dynamic coordination; Segmental and intersegmental coordination; Hand coordination, oculus-manual and graph-motor ability; Structuring of the notion of space; Structuring of the nation of time; Laterality. For each of the capacities listed above, six behavioural indicators (items) of progressive complexity have been identified and describe the degree of approach of the subject to the conquest of the ability object of observation.

Each item of the different psychomotor skills is evaluated with five motor tests, which do not require the predisposition of particular situations, representing in fact the normal activities that are conducted during the lessons of motor education. This avoids the risk of artificiality of the assessment. Specifically, the performance battery contains a total of 36 tests divided into six capacities declined, in turn, in 6 Behavioural Indicators (Item) of progressive complexity, which correspond respectively 5 tasks engines, for a total of 180 exercises.

The score assigned to each activity varies from 0 to 2 , in which 2 is attributed to the subject who carries out the motor task autonomously, 1 indicates when the performance is completed in the presence of help from the adult and 0 indicates the situation in which the child does not complete the task, although in the presence of help (Cottini L., 2003).

Table 1. List of capabilities from the MOVIT test (Cottini, 2003).

$\begin{array}{ll}\text { Capability. } 1 & \text { Muscle tone and relaxation } \\ \text { Capability. } 2 & \text { Balance and general dynamic coordination } \\ \text { Capability. } 3 & \text { Segmental, intersegmental coordination } \\ \text { Capability. } 4 & \text { Oculus-manual coordination, graph-motor ability, } \\ \text { Capability. } 5 & \text { Structuring the concept of space } \\ \text { Capability. } 6 & \text { Structuring the notion of time. }\end{array}$

\section{Research objectives}

In the light of the current state of the art and the regulatory framework referred to, this research has set itself the objective of investigating the typical and possibly atypical motor development of subjects, wanting to explore a lower target age, from the age of 3 to understand how much a child has, from the age of 3 , perception of both himself and the context. Therefore, the main purpose is to identify the developmental stage, which is at first present, and subsequently the potential of the child.

MOVIT tests, in fact, allow to evaluate the motor skills, probable deficits and the degree of potential development of the person observed in his environment and in interaction with others. In addition to the type of tasks, the fact sheets describing the evaluation tests related to the various items also indicate the definition of the level of performance and the actions that may be applicable. It is important that the help described in the data sheets is provided to the subject only after it has been established that he or she is not able to express himself or herself a correct level of performance. 


\section{Sample}

The sample object of the research was identified in a sample of convenience, an Italian educational circle ( $\mathrm{n}$ $=84,3-5$ years) consisting only of children who have completed the administration in and out of the chosen test.

\section{Research plan}

The six-month project included 2 meetings per week for each class, each lesson lasting 1 hour, for a total of 40 hours. The two test batteries were administered through two evaluation processes in two stages: the first in January and the second in April.

The children, moreover, stimulated and involved in recreational-motor experiences have had the opportunity to experiment with new movements that have led them to the discovery and knowledge of their own body. The game is the methodological tool that has accompanied the entire research process, moreover, these activities being carried out in communities have an important social value, resulting in an emotional-emotional involvement, shared between participants (Casolo F., 2007). The intervention of the experimenters was participatory, so as to involve the children to discover the rules of playing together, stimulating the child to seek adequate answers to the problems posed by trial and error, encouraging them to make reasoned choices and reflect on actions.

\section{RESULTS}

The data were recorded and processed through descriptive statistics (PSPP software). A variance analysis (ANOVA) was carried out to compare the average values of the different capacities analysed between different age groups (3, 4 and 5 years) and a two-tailed T-Test Student for each individual capacity and for each age group.

\section{DISCUSSION}

Table 2. describes the statistical data concerning the number of subjects for each age group, the Average, the Standard Deviation, the Minimum and Maximum values, for each capacity. The resulting averages in and out, for the 6 capacities divided by age classes, were compared through a two-line T-Test Student, to determine the significance.

Capacity is given by the mean value.

The difference between Test and Re-test in children of 3-4 and 5 years for the various capacities, is always significant. However, it emerges that there is a greater difference between Test and Re-test in Capacity 2 "Balance and General Dynamic Coordination", in Capacity 3 "Segmental and Inter-segmental Coordination" for 4-year-olds and in Capacity 4 "Oculus-manual coordination and graph-motor ability".

This data, in consideration of the capacities analysed, would seem to confirm that the MOVIT tests are effective in the detection of the Zone of Proximal Development of the child.

Analysis of the data shows that the variance (as per Standard Deviation) rises around three years, while it decreases within the age classes inversely to growth. This finding, covering a very heterogeneous three-year sample, shows that context and genetics modify the child's evidence. In conclusion, a variance analysis 
(ANOVA) was carried out to compare the mean values of the different capacities analysed between different age groups (3-4 and 5 year).

Table 2. Descriptive statistics (Statistic Software PSPP).

\begin{tabular}{|c|c|c|c|c|c|c|}
\hline Capability & 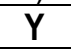 & $N$ & Mean & SD & Min & Max \\
\hline Cap1_Test & 3 & 23 & 17.82 & 2.30 & 12 & 23 \\
\hline \multirow[t]{3}{*}{ Tone \& relaxationT } & 4 & 29 & 32.17 & 2.85 & 25 & 38 \\
\hline & 5 & 32 & 36.94 & 2.92 & 33 & 46 \\
\hline & Tot & 84 & 30.20 & 8.22 & 12 & 46 \\
\hline Cap1_Retest & 3 & 23 & 29.23 & 3.87 & 22 & 38 \\
\hline \multirow[t]{3}{*}{ Tone \& relaxationT } & 4 & 29 & 37.97 & 4.18 & 28 & 45 \\
\hline & 5 & 32 & 42.31 & 3.75 & 35 & 48 \\
\hline & Tot & 84 & 37.33 & 6.52 & 22 & 48 \\
\hline Cap2_Test & 3 & 23 & 22.14 & 1.61 & 20 & 25 \\
\hline \multirow[t]{3}{*}{ Balance \& gen_dyn_coordT } & 4 & 29 & 35.38 & 3.83 & 30 & 47 \\
\hline & 5 & 32 & 41.00 & 2.81 & 36 & 48 \\
\hline & Tot & 84 & 34.04 & 8.14 & 20 & 48 \\
\hline Cap2_Retest & 3 & 23 & 41.91 & 4.68 & 32 & 52 \\
\hline \multirow[t]{3}{*}{ Balance\&gen_dyn_coordRT } & 4 & 29 & 41.93 & 3.93 & 33 & 49 \\
\hline & 5 & 32 & 45.44 & 2.95 & 39 & 49 \\
\hline & Tot & 84 & 43.28 & 4.14 & 32 & 52 \\
\hline Cap3_Test & 3 & 23 & 19.86 & 3.55 & 8 & 25 \\
\hline \multirow[t]{3}{*}{ Segm\&Intersegm_coordT } & 4 & 29 & 33.21 & 3.93 & 25 & 42 \\
\hline & 5 & 32 & 41.91 & 2.83 & 37 & 48 \\
\hline & Tot & 84 & 33.02 & 9.42 & 8 & 48 \\
\hline Cap3 Retest & 3 & 23 & 33.73 & 5.62 & 24 & 48 \\
\hline \multirow{3}{*}{ Segm \& Intersegm_coordRT } & 4 & 29 & 40.03 & 4.78 & 30 & 46 \\
\hline & 5 & 32 & 46.41 & 2.89 & 38 & 52 \\
\hline & Tot & 84 & 40.82 & 6.71 & 24 & 52 \\
\hline Cap4_Test & 3 & 23 & 16.23 & 1.90 & 12 & 20 \\
\hline \multirow[t]{3}{*}{ Ocman_coord \& graphmot_abT } & 4 & 29 & 26.86 & 3.15 & 21 & 35 \\
\hline & 5 & 32 & 29.53 & 2.68 & 24 & 35 \\
\hline & Tot & 84 & 25.07 & 6.07 & 12 & 35 \\
\hline Cap4_Restest & 3 & 23 & 26.05 & 3.98 & 20 & 37 \\
\hline \multirow[t]{3}{*}{ Ocman_coord \& graphmot_abRT } & 4 & 29 & 32.00 & 3.05 & 25 & 37 \\
\hline & 5 & 32 & 32.81 & 2.64 & 25 & 36 \\
\hline & Tot & 84 & 30.73 & 4.25 & 20 & 37 \\
\hline Cap5_Test & 3 & 23 & 22.36 & 4.50 & 8 & 27 \\
\hline \multirow[t]{3}{*}{ Struct conc_spaceT } & 4 & 29 & 36.00 & 4.04 & 28 & 45 \\
\hline & 5 & 32 & 45.19 & 4.09 & 38 & 54 \\
\hline & Tot & 84 & 35.93 & 10.00 & 8 & 54 \\
\hline Cap5_Retest & 3 & 23 & 37.32 & 4.85 & 30 & 50 \\
\hline \multirow[t]{3}{*}{ Struct_conc_spaceRT } & 4 & 29 & 39.90 & 4.04 & 31 & 46 \\
\hline & 5 & 32 & 49.25 & 2.87 & 39 & 55 \\
\hline & Tot & 84 & 42.82 & 6.48 & 30 & 55 \\
\hline Cap6_Test & 3 & 23 & 16.18 & 3.05 & 6 & 21 \\
\hline \multirow[t]{3}{*}{ Struct_conc_TimeT } & 4 & 29 & 28.34 & 2.96 & 20 & 34 \\
\hline & 5 & 32 & 32.53 & 3.04 & 27 & 37 \\
\hline & Tot & 84 & 26.73 & 7.26 & 6 & 37 \\
\hline Cap6_Retest & 3 & 23 & 27.95 & 3.71 & 23 & 37 \\
\hline \multirow[t]{3}{*}{ Struct_conc_TimeRT } & 4 & 29 & 32.93 & 3.01 & 24 & 36 \\
\hline & 5 & 32 & 35.06 & 1.39 & 31 & 37 \\
\hline & Tot & 84 & 32.43 & 3.94 & 23 & 37 \\
\hline
\end{tabular}


Assumed that the child, during the growth, improves its capacity of perception and action as the Central Nervous System, body development and motor-sense develop and mature, ANOVA between age groups shows that the average value grows in direct proportion to age, providing a comparison of average values between age groups always significant. The $p$ value per gender of ANOVA, however, shows no significant relevance between boys and girls ( $p$ value always $>.05$ ).

\section{CONCLUSIONS}

The most valuable investigative technique for teachers appears to be direct observation, which allows children to record the smallest changes, placing them in objective observation grids, in an ecological environment, which is more reassuring and gives greater assurance of data reliability (Eid L., Bussetti M., 2010). The test also demonstrates a significance of the data for all age groups observed and confirms the effectiveness of recreational-motor activity accompanied by a preventive tool, such as Movit Trials.

The creation of natural learning environments, directed to the awareness of one's own corporeality and the identification of creative thought in action and movement, can be a component that contributes significantly not only to the improvement of motor mastery, but also to foster the development of other motor and cognitive abilities that are related to the child's development potential as emerged from this study.

The observation of the child in a spontaneous context, of pleasure, not only favours the relationship between peers who must not, meanwhile, respond to performance requests - in which they would stand out mercilessly the more and the less good - but above all it allows the identification of that famous potential of learning (Vygotskij, 1966) that Vygotskij calls Zone of proximal development, from which it has the possibility to define for it gradual objectives of improvement, so "situated" as it takes into account the child's prerequisites and "effective", because it responds to the needs, motivations, interests of the recipient of the educational intervention.

It is possible to confirm how much the recreational-motor activity favours the development of different potentialities of the child, starting from the corporeal-functional one, to the cognitive one, from the one of the personalities to that of the social dimension. However:

"The movement at school (and more generally in education) is frightening. Educators, teachers are not trained to accept it, to welcome (to transform, educate them) the impulses and emotional discharges that inevitably accompany it. [...] an experienced, introjected and not only studied body pedagogy is needed so that the adult educator is genuinely made sensitive to recognizing the profound needs that the child expresses mostly through play and movement, regardless of whether they are expressed or inhibited» (Gamelli I, 2015).

The educator therefore has a double task: to propose activities that are to be placed in this "zone of proximal development", but at the same time to propose activities that present difficulties, and that are in this way motivational and functional to a learning. It is important that educational programming is able to recognize that the motor activity of the child is directly linked to the acquisition of higher cognitive levels and that this is closely linked to the environment in which it lives and grows. And it is for this reason that through the stimulation of the sensory-motor apparatus, and the achievement of the fundamental stages of development of the erect station, of the ambulation, the child is able to build his own identity and to know himself in the world and the world itself (Albanese A., Pavan B., 1990). 
Learning processes must be related to the context in the relationship with an agent body that interacts with the world; man evolved through neural resources that were initially devoted primarily to perceptual and motor processing, and whose cognitive activity consisted largely in the immediate environmental mutual influence.

Cognition, rather than being traced purely to processes of reworking of a central type, is actually based on mechanisms of coding and decoding peripheral, but which has its roots in processing sense-motor. In conclusion, it can be said, that the true place of cognitive activity is situated in the body and in the context of the real-world environment, and intrinsically implies perception and action (Sibilio M., 2002).

\section{AUTHOR CONTRIBUTIONS}

Pallonetto L., Ph.D. Student in Didactic Corporealities, Technology and Inclusion, at the Department of Human Sciences, Philosophy and Education of the University of Salerno, research fields: "Methods, Results and Discussion"; Perrone R., Ph.D. Student in Didactic Corporealities, Technology and Inclusion, at the Department of Human Sciences, Philosophy and Education of the University of Salerno, research field: "Conclusions"; Palumbo C., Associate professor of Methods and Didactics of Motor Activities (SSD M-EDF / 01), at the Department of Human Sciences, Philosophy and Education of the University of Salerno, as a Scientific Curator, research field: "Introduction".

\section{REFERENCES}

Aucouturier B., (2007). II metodo Aucouturier: i fantasmi d'azione e Pratica Psicomotoria, Franco Angeli, Milano.

Albanese A., Pavan B., (1990). "Quale psicomotricità?", Edizioni del Cerro, Pisa.

Casolo, F., (2007). Lineamenti di teoria e metodologia del movimento umano, Vita e pensiero, Milano.

Chow, J. Y., Davids, K., Button, C., Shuttleworth, R., Renshaw, I., \& Araújo, D. (2007). The Role of Nonlinear Pedagogy in Physical Education. Review of Educational Research, 77(3), 251-278. https://doi.org/10.3102/003465430305615

Cottini, L., (2003). Psicomotricità. Valutazione e metodi nell'intervento. Carocci Editore, Roma.

Downing G., (1995). II corpo e la parola, Astrolabio, Roma.

Eid, L., Bussetti, M., (2010). Come acquisire le competenze motorie nella scuola dell'infanzia. Atti del Seminario di Studio di Luino.

Formenti L., (2006). Psicomotricità, Educazione e Prevenzione, la progettazione in ambito socioeducativo, Erickson, Trento.

Gallese V. in Gison G., Bonifacio A., Minghelli E. (2012). Autismo e psicomotricità ,Erickson, Trento.

Gamelli I., (2015). Recensione al testo di Aucouturier B. Il bambino terribile a scuola, proposte educative e pedagogiche, Raffaello Ortina, Milano, in Rivista Psicomotricità educazione, riabilitazione, terapia, Volume 1, Numero 2 (54) - giugno 2015, Erickson, Trento.

Kirk, D., \& MacPhail, A. (2002). Teaching Games for Understanding and Situated Learning: Rethinking the Bunker-Thorpe Model, Journal of Teaching in Physical Education, 21(2), 177-192. https://doi.org/10.1123/itpe.21.2.177

Lucisano, P. \& Salerni, A., (2002). Metodologia della ricerca in educazione e formazione., Carocci, Roma. Muratori, F., (2008), Rivista Infanzia e adolescenza, vol. 7-n 1, articolo a cura di Nuovi panorami clinici della psichiatria della nuova infanzia, Pensiero Scientifico editore, Roma.

Palumbo C., (2018). II corpo inclusivo. Educazione, espressività e movimento, EdiSES, Napoli.

Sibilio M., (2008). II corpo e il movimento, Cuen Editore, Napoli.

Sibilio M., (2002). II corpo intelligente, Ellissi Editore, Napoli. 
Vygotskij Lev, S., (1966). II ruolo del gioco nello sviluppo mentale del bambino, in J.S. Bruner, A. Jolly, K. Sylva (a cura di), II Gioco. Ruolo e sviluppo del comportamento ludico negli animali e nell'uomo. Armando Editore, Roma.

\section{Regulatory references}

D.M. n. 254 del 16 novembre 2012 in G.U. n. 30 del 5 febbraio 2013 - Indicazioni nazionali per il curricolo della scuola dell'infanzia e del primo ciclo d'istruzione, 4 settembre.

Decreto Legislativo n. 65/2017, Istituzione del sistema integrato di educazione e di istruzione dalla nascita sino a sei anni.

Decreto Presidente della Repubblica 12 febbraio 1985, n. 104. Approvazione dei nuovi programmi per la scuola primaria.

\section{(c) $(7) \ominus$}

This work is licensed under a Attribution-NonCommercial-NoDerivatives 4.0 International (CC BY-NC-ND 4.0). 